This document was prepared in conjunction with work accomplished under Contract No. DE-AC09-96SR18500 with the U.S. Department of Energy.

This work was prepared under an agreement with and funded by the U.S. Government. Neither the U. S. Government or its employees, nor any of its contractors, subcontractors or their employees, makes any express or implied: 1 . warranty or assumes any legal liability for the accuracy, completeness, or for the use or results of such use of any information, product, or process disclosed; or 2 . representation that such use or results of such use would not infringe privately owned rights; or 3 . endorsement or recommendation of any specifically identified commercial product, process, or service. Any views and opinions of authors expressed in this work do not necessarily state or reflect those of the United States Government, or its contractors, or subcontractors. 
PVP2008-61390

\title{
HYDROGEN EFFECTS ON THE FRACTURE TOUGHNESS PROPERTIES OF FORGED STAINLESS STEELS
}

\author{
Michael J. Morgan, Savannah River National Laboratory, Aiken, SC 29808-0001
}

\begin{abstract}
The effect of hydrogen on the fracture toughness properties of Types 304L, 316L and 21-6-9 forged stainless steels was investigated. Fracture toughness samples were fabricated from forward-extruded forgings. Samples were uniformly saturated with hydrogen after exposure to hydrogen gas at $34 \mathrm{MPa}$ or 69 and $623 \mathrm{~K}$ prior to testing. The fracture toughness properties were characterized by measuring the J-R behavior at ambient temperature in air. The results show that the hydrogen-charged steels have fracture toughness values that were about $50-60 \%$ of the values measured for the unexposed steels. The reduction in fracture toughness was accompanied by a change in fracture appearance. Both uncharged and hydrogen-charged samples failed by microvoid nucleation and coalescence, but the fracture surfaces of the hydrogen-charged steels had smaller microvoids. Type 316L stainless steel had the highest fracture toughness properties and the greatest resistance to hydrogen degradation.
\end{abstract}

\section{INTRODUCTION}

Recent developments toward a hydrogen-energy economy have resulted in a greater interest in the effects of hydrogen on the structural properties of alloys. At Savannah River, the primary materials used in the construction of pressure vessels used for the containment of hydrogen isotopes are Types 304L, 21-6-9 and 316L stainless steel. In general, these vessesl are constructed from high-energy-rate-forged (HERF) stainless steels because of their high strength and compatibility with hydrogen. In recent years, there is an increasing interest in conventionally forged (CF) stainless steels because of their greater availability from commercial vendors.

For many years, the forming process of choice for reservoir manufacturing was high-energy-rate forging (HERF), principally because the DOE forging facility owned only HERF hammers. Today, some reservoir forgings are being made that use a conventional, more common process known as press forging (PF or CF) (1). One of the chief differences between the two forging processes is strain rate: Conventional hydraulic or mechanical forging presses deform the metal at 4-8 ft/s, about ten-fold slower than the HERF process.

HERF steels are highly resistant to, but not immune from, structural property degradation during their service life that results from the dissolution and diffusion of hydrogen isotopes into the vessel walls. While the effect of hydrogen on the mechanical properties of HERF steels are well characterized, its effect on fracture toughness properties are not. Furthermore, the effect of forging microstructure on hydrogen compatibility is also not well developed.

The changes are manifested by reduced volume ductility during reservoir burst tests and slow crack growth during longterm life storage tests. The change in properties has been attributed to hydrogen embrittlement of the microstructure that is made worse because of presence of helium-3 from tritium decay(1). Typically, steels with decay helium bubble microstructures are hardened and less able to deform plastically, and become more susceptible to embrittlement by hydrogen and its isotopes (1-8).

Material specifications and quality control continue to provide successful stockpile performance, and long-term life storage tests have demonstrated the tritium compatibility of reservoirs steels. However, fracture-toughness properties are needed for modeling efforts and for designing and establishing longer tritium reservoir lifetimes, ranking materials and their behavior, and, potentially, for qualifying new steels and forging vendors or processes.

This study had two purposes. The first purpose was to measure the fracture-toughness properties of Type 316L stainless steel in the uncharged and hydrogen-charged condition and to compare the results to those measured previously for Types 304L and 21-6-9 stainless steels. The 
Table I - Compositions of Stainless Steel Forgings, Plates and Weld Filler Wires (Weight \%)

\begin{tabular}{lccccccccccccc}
\hline & Cr & Ni & Mn & Mo & C & Si & P & S & N & Co & O & Al & Cu \\
\hline HERF 316L & 17.2 & 13.2 & 1.8 & 2.1 & .022 & 0.55 & .013 & .002 & .06 & & .002 & - & .069 \\
CF 304L & 18 & 11.3 & 1.7 & .039 & .024 & 0.42 & 0.007 & 0.003 & 0.036 & 0.027 & - & -- & - \\
HERF 21-6-9 & 19.4 & 6.4 & 8.5 & - & .04 & .33 & .021 & $<.001$ & .28 & - & .0022 & $<.001$ & - \\
$\begin{array}{l}\text { CF-21-6-9 } \\
\text { Heat A }\end{array}$ & 19.1 & 6.7 & 9.9 & - & .03 & .41 & .01 & .004 & .28 & - & .001 & .005 & - \\
$\begin{array}{l}\text { CF-21-6-9 } \\
\text { Heat B }\end{array}$ & 19.3 & 6.7 & 9.9 & - & .03 & .38 & .01 & .001 & .28 & - & .002 & .004 & -
\end{tabular}

*304L composition from ICPES analysis; all other heats are manufacturers' supplied compositions.

**Filler wire used for Types 304L and 21-6-9 weldments

HERF - high-energy-rate forged

CF - conventionally forged

second purpose was to measure the effect of hydrogen on the fracture toughness properties of conventionally forged steels and compare them to high-energy-rate forged steels.

\section{EXPERIMENTAL PROCEDURE}

Fracture toughness samples were fabricated from Types 304L, 316L, and 21-6-9 stainless steel forgings. The compositions of the steels used in the study are listed in Table I. The material was supplied in the form of forward extruded cylindrical forgings, either HERF or CF. The mechanical properties of the forgings are shown in Table II. Arc-shaped fracture-mechanics specimens having the shape and dimensions shown in Fig. 1 were fabricated from the forgings so that the crack would propagate radially and the crack face was parallel to the axis of the forging. The samples were fatigue-cracked a so that the crack-length to sample-width ratio was between 0.4 and 0.6 .

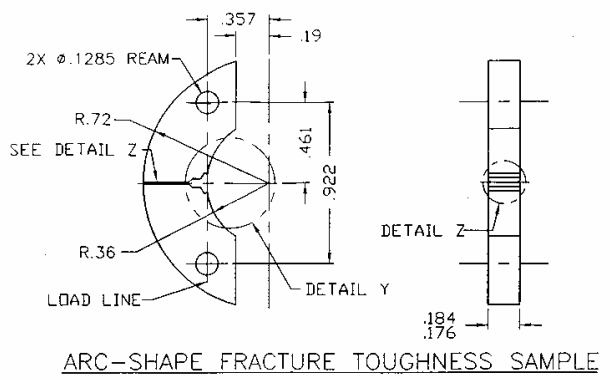

Figure 1. Shape and Dimensions of Fracture-Toughness Sample. Dimensions shown are in Inches.

Samples of each of the steels were tested in air at ambient temperature in the as-forged condition. Companion samples were exposed to either hydrogen gas at $623 \mathrm{~K}$ and an overpressure of $34.5 \mathrm{MPa}$ or $69 \mathrm{MPa}$ and then stored in air at 223 $\mathrm{K}$. The temperature of exposure was designed to uniformly saturate the samples with hydrogen while minimizing any change in the steel microstructure; the storage temperature was designed to minimize off-gassing until testing was performed. The concentration of hydrogen in the steels was calculated from the charging pressures and temperatures and the solubility parameters of C. San Marchi, et al. (9). The hydrogen concentration in Types 304L and 316L stainless steels was calculated to be 3730 atomic parts per million (appm) for the $34.5 \mathrm{MPa}$ charging pressure and 6130 appm for the $69 \mathrm{MPa}$ charging pressure. For Type 21-6-9 stainless steel, the hydrogen concentration was calculated to be 5560 appm for the 34.5 MPa charging pressure and 9140 appm for the $69 \mathrm{MPa}$.

J-integral tests were conducted at room temperature in air using a screw-driven testing machine and a crosshead speed of $0.002 \mathrm{~mm} / \mathrm{s}$ while recording load, load-line displacement with a gage clipped to the crack mouth, and crack length. Crack length was monitored using an alternating DC potential drop system and guidelines described in ASTM E647-95 (5). Figure 2 shows the heat-tinted sample that was pulled apart after the J-R test. The length of the initial fatigue crack and the length of the crack after the J-R test were used to calibrate the DC potential drop system.

Table II - Mechanical Properties

\begin{tabular}{lccc}
\hline MATERIAL & $\begin{array}{c}\text { YIELD } \\
\text { STRENGTH } \\
\text { (MPA) }\end{array}$ & $\begin{array}{c}\text { ULTIMATE } \\
\text { STRENGTH } \\
\text { (MPA) }\end{array}$ & \% EL \\
\hline HERF 316L & 443 & 736 & 40.3 \\
CF 304L & 462 & 724 & 47.6 \\
$\begin{array}{l}\text { CF 21-6-9 } \\
\text { HEAT A }\end{array}$ & 685 & 960 & 44.3 \\
CF 21-6-9 & 600 & 906 & 48.3 \\
HEAT B & & 961 & 37.6 \\
HERF 21-6-9 & 723 & &
\end{tabular}




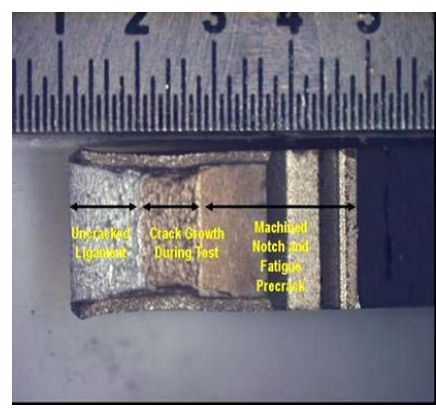

Figure 2. Heat-Tinted Fracture Appearance After J-R Test.

The J-Integral versus crack length increase ( $\mathrm{J}$ vs. da) curves were constructed from the data using ASTM E1820-99 (6). The $J_{Q}$ value is defined as the material fracture toughness value and was obtained from the intercept of an offset from the crack tip blunting line with the J-da curve.

\section{RESULTS}

Typical load-displacement records from the fracture toughness tests for the uncharged and hydrogen-charged samples are shown in Figure 3. The hydrogen-charged sample records typically displayed a sharper load drop after maximum load with increasing displacement than did the uncharged sample records. Also, the area under the load-displacement plot, which is proportional to the energy of fracture and is used in the J- Integral analysis, were smaller for the hydrogencharged samples than the uncharged samples. Figure 4 shows the crack extension with increasing displacement for the uncharged and hydrogen-charged samples. Note that crack extension was larger with increasing displacement for hydrogen-charged samples.

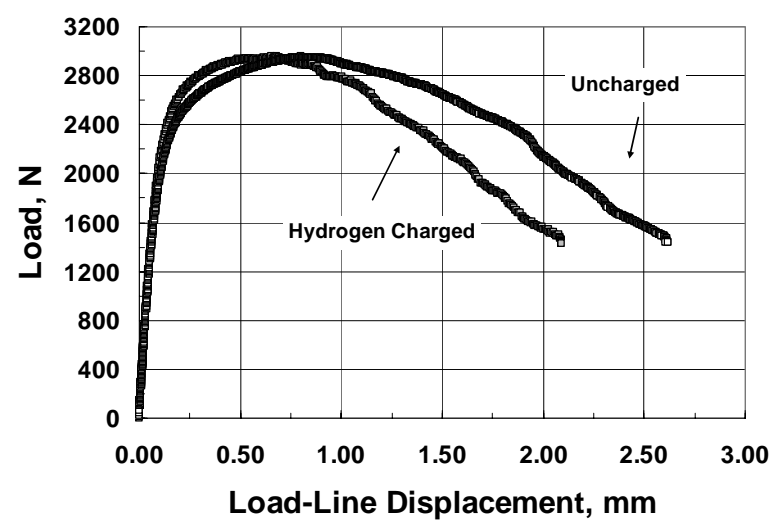

Figure 3. Typical Load-Displacement Behavior for Uncharged and Hydrogen-Charged Samples During J-Integral Test.

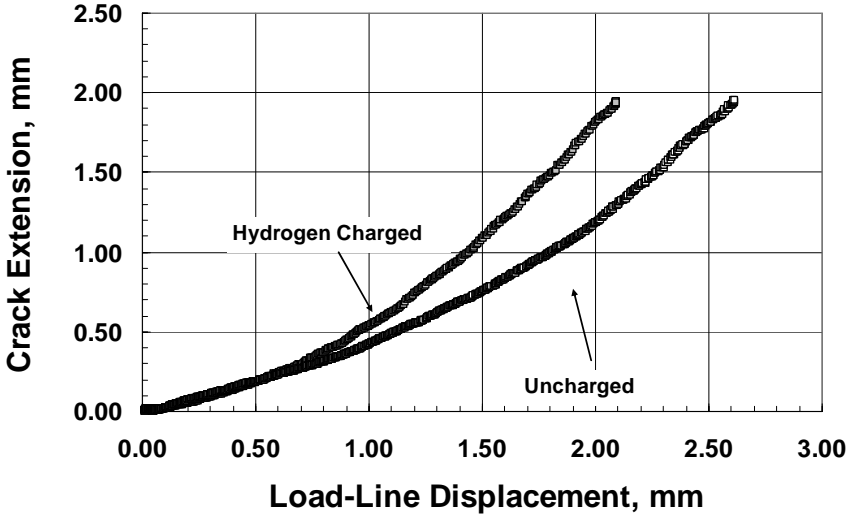

Figure 4. Typical Crack Extension Behavior for Uncharged and Hydrogen-Charged Samples During J-Integral Test.

The J-integral fracture toughness data were determined from the load-displacement-crack length records and the crack growth data and plots of the J-Integral versus crack extension, per ASTM 1820 were constructed (J-R plots). Figure 5 shows the J-R plots for the uncharged and hydrogen-charged samples. The fracture toughness value, $\mathrm{J}_{\mathrm{Q}}$, is determined by the intercept of the J-R curve with the offset line. The data were remarkably consistent with small sample-to-sample variations for both the uncharged and hydrogen-charged samples. Note that Fig. 5 shows that the hydrogen-charged samples had J-R curves lower than uncharged samples and that the fracture toughness values $\left(\mathrm{J}_{\mathrm{Q}}\right)$ as determined from the intercept of the J-R curve with the offset line were lower for hydrogen-charged samples. Similar behavior was observed for the other steels.

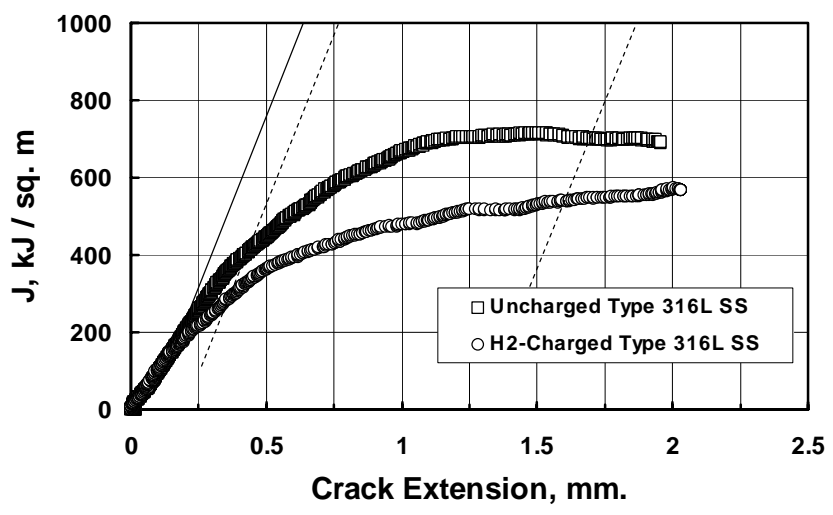

Figure 5. Comparison of the J-Integral (J) vs. Crack Extension Curves for Uncharged and Hydrogen-Charged HERF 316L Stainless Steel Samples. 


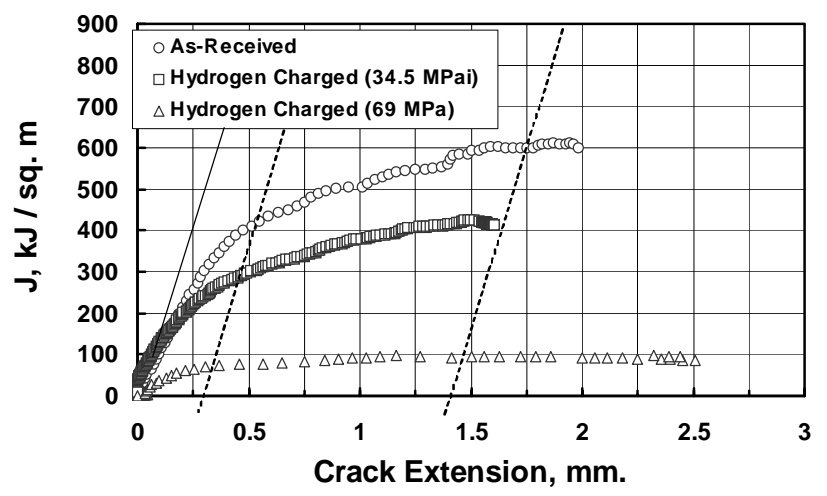

Figure 6. J-Integral $(J)$ vs. Crack Extension Curves for Uncharged and Hydrogen-Charged Type 21-6-9 Stainless Steel in the Conventionally Forged Condition.

A second purpose of this study was to investigate the effect of hydrogen pressure on the fracture toughness properties. Figure 6 shows the large fracture toughness reductions after hydrogen exposures of 5000 psi and 10000 psi. Similar reductions were observed for the other heats tested. These results are summarized in Figures 7 and 8 which shows the effect of hydrogen charging pressure and forging condition on the fracture toughness properties of the three steels. HERF Type 316L stainless steel had the highest uncharged and hydrogen-charged fracture toughness value. HERF Type 21-6-9 stainless steel had the lowest. The fracture toughness properties of CF Type 21-6-9 stainless steel were higher and more resistant to hydrogen than the HERF steel (Fig. 8)

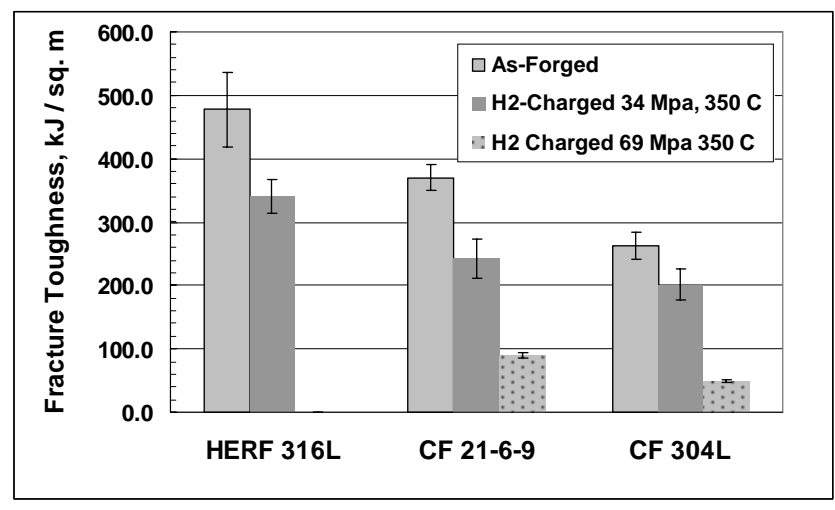

Figure 7. JQ Fracture Toughness Values Measured for Types 316L, 21-6-9, and 304L Stainless Steels in the Uncharged and Hydrogen-Charged Conditions.

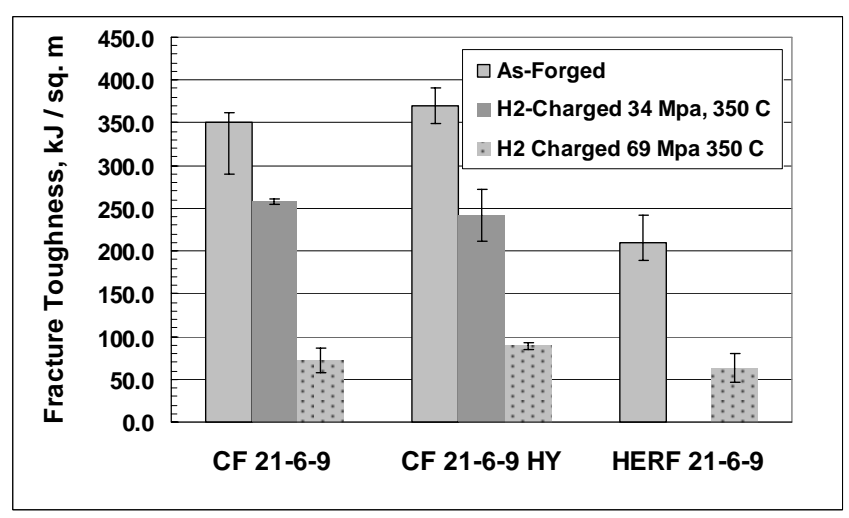

Figure 8. JQ Fracture Toughness Values Measured for Conventionally Forged and High-Energy-Rate Forged Type 216-9 Stainless Steels in the Uncharged and Hydrogen-Charged Conditions.

Figure 7 shows that, for Type 316L stainless steels, the uncharged steels had an average fracture toughness value of $480 \mathrm{MPa}$ and the hydrogen-charged steels had an average value of $350 \mathrm{MPa}$ (three tests each). Thus, the hydrogen-charged samples had a fracture toughness value that was $71 \%$ of the unexposed steels. Similar hydrogen-induced reductions in can be gleaned from Figs. 7 and 8 for the other alloys. The results indicate that Type 316L stainless steel has the best fracturetoughness properties and overall resistance to hydrogen effects.

The fracture appearance of the of one of the hydrogenexposed alloys is shown in Figure 9. The effect of hydrogen is dramatic in that the size of the microvoids on the fracture surface is greatly reduced. This was observed for the other alloys as well.

The fracture mode of both uncharged and hydrogencharged samples was by microvoid nucleation, growth, and coalescence (Fig. 9). Microvoids nucleate at nonmetallic inclusions in the steel (sulfides, oxides, etc) and grow under strain until they coalesce at fracture. The microvoids on the hydrogen-charged fractures were smaller and more closely spaced than those on the uncharged fractures.

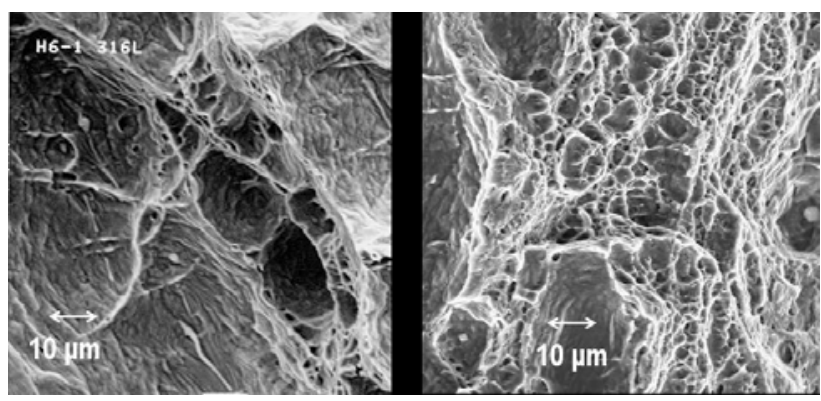

(a)

(b)

Figure 9. Comparison of the Fracture Appearance for Type 316L Stainless Steel Sample: (a) Uncharged and (b) HydrogenCharged. 


\section{DISCUSSION}

The HERF Type 316L stainless steel used in this study had excellent fracture-toughness properties. The unexposed steels had an average toughness value that was more than twice as high as the fracture toughness value of HERF Type 21-6-9 steel (Compare Figs. 7 and 8). Part of the difference can be explained by the fact that the HERF Type 21-6-9 steel had been sensitized which reduced its toughness (8). Nevertheless, the toughness of HERF Type 316L was still 25-65\% higher than the conventionally forged heats of Types 304L and 21-6-9 (Figure 6). Part of the difference can be attributed to the higher yield strength of HERF Type 21-6-9 when compared to HERF Type 316L. Fracture toughness will decrease with increasing yield strength. Another factor though, that contributes to toughness is the nickel content difference. Type 316L stainless steel has higher nickel content than either Type 304L or Type 21-6-9 stainless steel and nickel is a well-known toughening agent in alloy steels.

Nickel is also an important factor in resistance to hydrogen embrittlement. Caskey (12) showed that retained ductility after hydrogen exposure was maximized for $\mathrm{Fe}-\mathrm{Cr}-\mathrm{Ni}$ alloys having nickel contents greater than $10 \%$. The Type 316L stainless steel used in this study had a nickel content of $13 \%$ while the Type 304L alloy had $~ 10 \%$ nickel and the Type 21-6-9 steels had $\sim 6.5 \%$ nickel. According to Caskey (12), molybdenum also appears to alleviate hydrogen damage when present in small amounts (12), 2-3\%, which it is for Type 316L stainless steel (Table I).

Crack nucleation, as measured by $\mathrm{J}_{\mathrm{Q}}$, and crack propagation, as measured by the shape of the J-R curve, were easier in hydrogen-charged stainless steels when compared to uncharged samples. This is consistent with the effects of hydrogen isotopes on fracture-toughness properties seen in earlier studies $(4,8,13)$. The observation that Type 316L stainless steel had the higher fracture-toughness properties than the other steels is in good agreement with those of earlier investigations by Robinson (1,2) and Caskey (12). In those studies, the fracture properties of both smooth and notched tritium-exposed-and-aged stainless steels decreased with increasing helium concentrations and tritium degassing caused a recovery of the fracture properties. It is also in agreement with the effect of tritium on fracture-toughness properties of these alloys (13)

The small voids on the fracture surface of the hydrogenexposed steels (Figure 9) are an indicator that hydrogen is weakening the interface cohesive strength of the particle-matrix interface. Microvoid nucleation and growth leads to void coalescence. The extensive deformation and microvoid growth away from the crack plane and that primary dimples are seen to be nucleated by the larger globular inclusions agrees with the observations of Mills $(14,15)$ for the general fracture of the unexposed steels. There are a number of different mechanisms of void coalescence.
In tougher materials, like the unexposed Type 316L stainless steel used in this study, the voids link up by strain on the ligament between them. The ligament will continue to stretch until there is no area remaining that can support the load. Another method of coalescence is void-sheet formation. This appears to be happening in the hydrogen-exposed alloys. Void sheet formation results from interface de-cohesion prior to the onset of ligament necking and is highly dependent on the size and interfacial strength of smaller second phase particles.

In the hydrogen-exposed steels, the interfacial strength of the second phase particles is weakened and, so, the toughness is reduced by the occurrence of void sheets, preempting the necking process $(16,17)$. Fine carbides are present throughout these microstructures in the as-forged condition. A weakening of the carbide/matrix interface by hydrogen will make it easier for microvoids to nucleate on very fine carbides that are present throughout the microstructure. The interfacial strength of $\mathrm{Cr}$ Mo carbides may be higher than the interfacial strength of pure Cr carbides, which would explain why Type 316L stainless steel is tougher and more resistant to hydrogen effects than Types 304L and 21-6-9 steels. Types 321 and 347 stainless steels, which use niobium and titanium as carbide formers, may have even greater resistance to hydrogen effects on toughness than Type 316L stainless steel.

\section{CONCLUSIONS}

1. HERF Type 316L stainless steel has good fracturetoughness properties and is highly resistant to hydrogen effects on toughness. Its fracture-toughness properties are higher than those measured for Types 304L and 21-6-9 stainless steels.

2. The hydrogen-exposed stainless steels had fracture toughness values that were $30 \%$ lower than the unexposed steels, but still retained good toughness properties. The hydrogen effect on toughness was indicated by lower $\mathrm{J}_{\mathrm{Q}}$ values and lower J-R curves.

3. Fracture modes of both unexposed and hydrogenexposed steels were by the microvoid nucleation and growth process. Microvoids on hydrogen exposed fractures were smaller and more closely spaced than those on unexposed fractures, which suggests that hydrogen-assisted fracture occurred by making microvoid nucleation easier.

\section{ACKNOWLEDGMENTS}

The author wishes to acknowledge the support from the U. S. Department of Energy (DOE) to the Savannah River National Laboratory (SRNL) under Contract No. DE-AC09-96SR18500. 


\section{REFERENCES}

1. S. L. Robinson, B. C. Odegard, Jr., N. Y. C. Yang, D. A. Hughes, and T. Headley, "Analysis of the Microstructure and Suitability of the First Commercial Forgings For Gas Transfer System Applications, SANDIA Report, SAND998243, October 1999, Sandia National Laboratories, Albuquerque, NM 87185 and Livermore, CA 94550.

2. S. L. Robinson, "Tritium and Helium on Plastic Deformation in AISI 316 Stainless Steel”, Materials Science and Engineering, 96 (1987), 7-16.

3. M. J. Morgan "The Effects of Hydrogen Isotopes and Helium on the Flow and Fracture Properties of 21-6-9 Stainless Steel”, Proc. Fine Symposium, ed. P. K. Liaw, J.R. Weertman, H. L. Marcus, and J. S. Santner, (Warrendale, PA: TMS, 1990), 105-111.

4. M. J. Morgan, M. H. Tosten, and S. L. West, "Tritium Effects on Weldment Fracture Toughness", Savannah River National Laboratory, WSRC-STI-00056, July 172006.

5. M. H. Tosten and M. J. Morgan, "Microstructural Study of Fusion Welds in 304L and 21Cr-6Ni-9Mn Stainless Steels (U)”, WSRC-TR-2004-00456, March, 2005.

6. M. H. Tosten and M. J. Morgan, "Transmission Electron Microscopy Study of Helium-Bearing Fusion Welds", WSRC-TR-2005-00477, November, 2005.

7. M. J. Morgan and M. H. Tosten, "Microstructure and Yield Strength Effects on Hydrogen and Tritium Induced Cracking in HERF Stainless Steel", Hydrogen Effects on Material Behavior, ed. N. R. Moody and A. W. Thompson, (Warrendale, PA: TMS, 1990), 447-457.

8. M. J. Morgan, S. L. West, and G. K. Chapman, "Tritium Aging Effects on Fracture Toughness of Type 21-6-9 Stainless Steel”, WSRC-TR-2007-00244, June, 2007.

9. C. San Marchi, B.P. Somerday and S.L. Robinson, "Permeability, Solubility and Diffusivity of Hydrogen Isotopes in Stainless Steels at High Gas Pressures", International Journal of Hydrogen Energy, Volume 32, Issue 1, January 2007, 100-116.

10. ASTM E647-95a "Standard Test Method for Measurement of Fatigue Crack Growth Rates" "1999 Annual Book of ASTM Standard Volume 3.01 Metals-Mechanical Testing; Elevated and LowTemperature Tests; Metallography, American Society for Testing and Materials, 1999.
11. ASTM E1820-99 "Standard Test Method for Measurement of Fracture Toughness", 1999 Annual Book of ASTM Standard Volume 3.01 Metals-Mechanical Testing; Elevated and Low-Temperature Tests; Metallography, American Society for Testing and Materials, 1999.

12. G. R. Caskey, Jr., "Hydrogen Effects in Stainless Steels", Hydrogen Degradation of Ferrous Alloys, ed. J. P. Hirth, R. W. Oriani, and M. Smialowski, eds., (Park Ridge, NJ: Noyes Publication, 1985), p. 822.

13. M. J. Morgan and M. H. Tosten, "Tritium and Decay Helium Effects on the Fracture Toughness Properties of Types 316L, 304L, and 21Cr-6Ni-9Mn Stainless Steels", Hydrogen Effects in Materials, ed. A. W. Thompson and N. R. Moody, (Warrendale, PA: TMS, 1996), p. 873.

14. W. J. Mills, "Fracture Toughness of Type 304 and 316 Stainless Steels and Their Welds", International Materials Reviews, 42 (2) (1997), 45-82.

15. W. J. Mills, "Heat-To-Heat Variations in the Fracture Toughness of Austenitic Stainless Steels", Engineering Fracture Mechanics, Vol. 30, No. 4, 469-492, 1988.

16. T. L. Capeletti and M. R. Louthan, Jr., "The Tensile Ductility of Austenitic Steels in Air and Hydrogen", Journal of Engineering Materials and Technology, Transactions of the ASME, Vol. 99 (1977), 153-158.

17. C. San Marchi, B. P. Somerday, X. Tang, G. H. Schiroky, "Effects of Alloy Composition and Strain Hardening on Tensile Fracture of Hydrogen-Precharged Type 316 Stainless Steel”, Int. J. Hydrogen Energy (2007), doi:10.1016/j.jhydene.2007.10.046. 